\title{
光干渉による潤滑膜厚計測
}

\author{
中野 健 $^{1} \cdot$ 田所千治 ${ }^{2} \cdot$ 前川 覚 $^{3}$ \\ 1横浜国立大学大学院環境情報研究院 函 240-8501 神奈川県横浜市保土ケ谷区常盤台 79-7 \\ 埼玉大学大学院理工学研究科３338-8570 埼玉県さいたま市兴区下大久保 255 \\ ${ }^{3}$ 鳥取大学大学院工学研究科 俨 680-8552 鳥取県鳥取市湖山町南 4-101
}

（2017 年 1 月 4 日受付；2017 年 1 月 25 日掲載決定）

\section{Measurements of Lubricant Film Thickness by Optical Interference}

\author{
Ken NAKANO ${ }^{1}$, Chiharu TADOKORO ${ }^{2}$ and Satoru MAEgawa ${ }^{3}$ \\ ${ }^{1}$ Yokohama National University, 79-7 Tokiwadai, Hodogaya-ku, Yokohama 240-8501 \\ ${ }^{2}$ Saitama University, 255 Shimo-Okubo, Sakura-ku, Saitama 338-8570 \\ ${ }^{3}$ Tottori University, 4-101 Koyama-cho Minami, Tottori 680-8552
}

(Received January 4, 2017 ; Accepted January 25, 2017)

\begin{abstract}
Optical interference is one of the most powerful tools for lubrication studies, since it enables in-situ measurements of lubricant film thickness under practical conditions. After various improvements, optical interferometry has been developed to apply not only to thick (e.g., micrometer-scale) films in hydrodynamic lubrication regime but also to thin (e.g., nanometer-scale) films in boundary lubrication regime. This paper reviews the principles of measuring lubricant film thickness by optical interferometry and some technical tips on methods using white-light spectroscopy.
\end{abstract}

KEYWORDS : friction, lubrication, adsorption, thin film, interferometry

\section{1.は じめに}

直径 $10 \mathrm{~mm}$ の鋼球を $10 \mathrm{~N}$ の負荷で鋼板と接触させる と, 鋼球と鋼板の弾性変形に由来する最大圧力は $1 \mathrm{GPa}$ に達する。見掛けの上では平凡な条件ながら, 実際には かくも過酷な（もしくはそれ以上に過酷な）摩擦界面に おいて, 機械の寿命を担保するために, 潤滑は必要不可 欠な技術である。

摩擦界面に形成される潤滑油の薄膜（潤滑膜）の役割 は，面外方向の負荷に逆らい 2 面を分離して，面内方向 になめらかな相対運動を実現することにある。したがっ て, 潤滑問題と向き合う際には, 対象とする摩擦界面の 接線抵抗がどれほど大きいか（摩擦力や摩擦係数）はも ちろんのこと，2面がどれだけ離れているか（潤滑膜 厚）が論点になる。本稿の主題「潤滑膜厚計測」の必要 性はそこにある。

E-mail : nakano@ynu.ac.jp
潤滑油の流体力学的な作用により, 表面粗さよりも十 分厚い潤滑膜を形成する形態を「流体潤滑」と呼ぶ。相 対運動する 2 面を非接触にする流体潤滑は, 機械の長寿 命を実現する理想的な潤滑状態だが，昨今のエネルギー 問題の要請から, 潤滑油の低粘度化が急速に進み, 分子 レベルの吸着膜等による超薄膜潤滑，すなわち「境界潤

滑」への期待と要求が高まっている。

本稿では, 古典的な手法ながらも，1960 年代から 様々な改良が重ねられ，今なお境界潤滑問題に対しても 有効な光干渉による潤滑膜厚計測の進展を紹介する。主 に本計測技術の利用を検討している研究者を想定して, 以下の話を進めたい。

\section{2. 光干渉による潤滑膜厚計測の概要}

\section{1 基本構成}

光干渉の潤滑面への適用は, Newtonによる光干渉の 発見 ${ }^{1)}$ から約 200 年後にあたる 1919 年, 最大静摩擦力 の研究において, Hardy と $\operatorname{Hardy}^{2}{ }^{2}$ が油膜の存在を捉え 
るために光干渉色を利用したことが最初の事例である。 その後, $\mathrm{Kirk}^{3)}$ は, 直交させたガラス円柱の摩擦界面に 形成された油膜厚さの空間分布を光干渉色により捉え, Cameron ら ${ }^{499}$ による実用に即した潤滑膜厚計測法の基 礎が築かれた。

主として Cameronの流れを汲む近年の潤滑膜厚計測 では, Fig. 1 に示すように，金属球の上にガラス板を配 置した点接触を用いることが多い。球と板の相対運動に より, 潤滑油が両者の間に引き込まれて, 摩擦条件に応 じた厚さの潤滑膜が形成される。なお，球の回転を拘束 して板を駆動すると「すべり摩擦」, 球を回転自由に支 持して板を駆動すると（連れ回りにより）「転がり接触」 になる。形成された潤滑膜の膜厚計測には，摩擦面を上 から落射照明型の光学顕微鏡で観察する構成が標準的で ある。

\section{2 計測原理}

Fig. 1 の摩擦界面（ガラス板-潤滑膜-金属球）の光学 モデルを Fig. 2（a）に示す。ガラス板から入射した光 は, ガラス板-潤滑膜の界面での反射光 (反射光 1) と 透過光にわかれ，透過光は潤滑膜一金属球の界面で反射 する (反射光 2$)$ 。潤滑膜を往復する光学距離が光路差 となり, 反射光 1 と反射光 2 の干渉が生じる。干渉光の 強度は潤滑膜厚の関数となり, 単色光を用いた場合は, 明暗の縞が現れる。明縞と暗縞の位置における潤滑膜厚 $h$ は，それぞれ次式で与えられる。

$$
\begin{aligned}
& \text { 明縞 }: h=\frac{\lambda}{2 n}(N-\varphi) \\
& \text { 暗縞 }: h=\frac{\lambda}{2 n}\left(N-\frac{1}{2}-\varphi\right)
\end{aligned}
$$

ここで, $\lambda$ は光の波長， $n$ は潤滑膜の屈折率， $N$ は縞次 数 $(N=1,2,3, \cdots), \varphi$ は金属面での反射の際に生じる 位相変化 $(\varphi>0)$ を表す。明暗の縞次数を数えること により, 目視でも縞間隔の分解能 $(\lambda / 4 n)$ で膜厚を計 測することができる。

\section{3 チップス：反射層とスペーサ層}

明嘹な干渉縞を得るためには，反射光 1 の強度を高め るために, 透明板の屈折率を潤滑油よりも高くする必要 がある。したがって, Cameron らの初期の研究では, 高 屈折率な透明板として, サファイアやダイヤ, 高屈折率 のガラスが用いられていた ${ }^{4 \sim 6)}$ 。現在では，ガラス板の 表面にクロムの薄膜を蒸着させて, 明瞭な干渉縞を得る 方法 ${ }^{8)}$ が主流である。クロムよりも吸収率の低いチタニ アを反射層とすれば，反射層と金属面の間で繰り返し透 過と反射が生じる多光束の光干渉となり, 明暸な暗縞が 得られるので, 縞位置をより高い精度で特定可能とな $ろ^{9)}$ 。

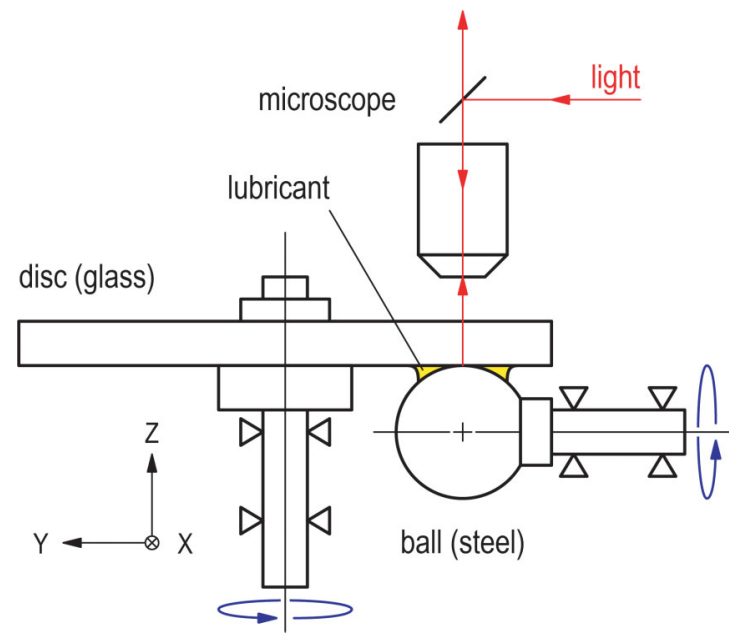

Fig. 1. (color online). Typical layout of apparatuses for measuring lubricant film thickness.

(a)

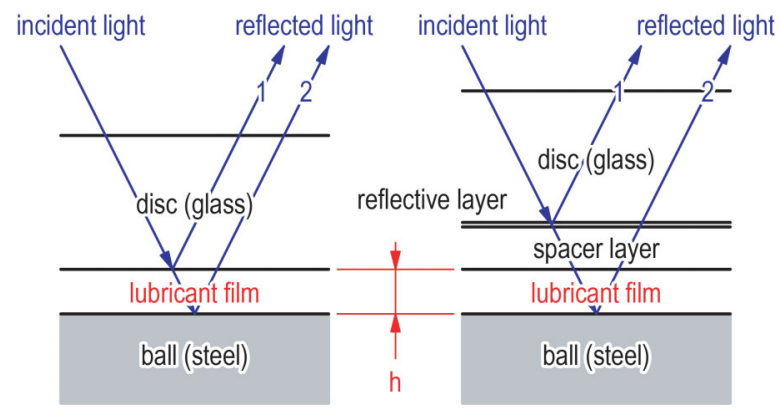

Fig. 2. (color online). Principle of measuring lubricant film thickness $h$ by two-beam interference; (a) without reflective layer and spacer layer; (b) with reflective layer and spacer layer.

反射層で縞のコントラストを上げたとしても，計測可 能な潤滑膜厚の下限は $60 \mathrm{~nm}$ 程度に留まる。それは, 膜厚が $\lambda / 4 n$ を下回ると, 膜厚に対する光強度の変化が 鈍感になるからである。そこで, Wastelakeらは, Fig. 2 (b) のように，クロムの反射層の上にシリカのスペーサ 層を蒸着させることで, 潤滑膜がない場合（すなわち $h=0 ） て ゙ も 十$ 分な光強度が得られるように光路を「嵩增 し」して, $\lambda / 4 n$ を下回る薄い潤滑膜の膜厚計測を可能 にした7)。なお，Fig. 2（b）の構成で単色光を用いた場 合，明縞と暗縞の位置における潤滑膜厚 $h$ は，それぞれ 次式で与えられる。

$$
\text { 明縞 }: h=\frac{\lambda}{2 n}(N-\varphi)-\frac{n_{\mathrm{SL}}}{n} h_{\mathrm{SL}}
$$


暗縞 : $h=\frac{\lambda}{2 n}\left(N-\frac{1}{2}-\varphi\right)-\frac{n_{\mathrm{SL}}}{n} h_{\mathrm{SL}}$

ここで, $h_{\mathrm{SL}}$ と $n_{\mathrm{SL}}$ は, それぞれスペーサ層の膜厚と 屈折率である。

\section{3. 光干渉による潤滑膜厚計測の分類}

\section{1 分類}

光干渉による潤滑膜厚計測の概要は 2 章で紹介したと おりだが，計測精度や利便性の向上を目指して，これま でに様々な工夫がなされてきた。それらは，1縞強度 法, (2)比色分析法, (3)白色分光法の 3 種類に大別するこ とができる。

\section{2 縞強度法}

縞強度法は，既知の波長の光を用いて干涉縞の縞次数 と強度から膜厚を求める手法である。Luo ら ${ }^{10)}$ は, 単色 光の 2 光束干渉モデルに基づき, 明縞と暗縞の相対干渉 強度から膜厚を算出する方法を提案し， $\lambda / 4 n$ 以下の潤 滑膜厚が計測可能であることを示した。Gao ら ${ }^{11}$ は，ク ロム反射層内部と潤滑膜内部の反射を考慮した多光束干 渉モデルに基づき, 最小膜厚 $1 \mathrm{~nm}$, 分解能 $1 \mathrm{~nm}$ の潤滑 膜厚計測が可能であることを示した。

また，縞強度法は，光の波長を限定するので，コヒー レンス長が長く, 厚膜の計測にも適している。この性質 を利用して, Bassani ら ${ }^{12)}$ は, 分解能 $\lambda / 4 n$, 最大 $2.5 \mu \mathrm{m}$ の潤滑膜厚計測が可能であることを示した。さらに，2 色光源 ${ }^{13,14)}$ や 3 色光源 ${ }^{15}$ を利用することにより, 高分解 能で広範囲な膜厚計測が可能となる。

\section{3 比色分析法}

比色分析法は, 白色光を用いた光干渉色の分析により 膜厚を求める手法である。Gustafsson ${ }^{16)}$ は, 干渉縞の デジタル画像の各ピクセルに埋め込まれた RGB 情報か ら色相（hue）を算出して，潤滑膜の 3D プロファイル を得た。ただし，本手法では，潤滑膜厚と色相の関係を 校正する作業が事前に必要となる。その後, Cann らは, 本手法をスペーサ層と組み合わせて, 薄膜計測を可能と する手法（SLIM : spacer layer imaging method）を確立し た ${ }^{17,18)}$ 。また, 白色光源の代わりに 3 色光源を用いた比 色分析法も開発されている ${ }^{19,20)}$ 。Hartl ら ${ }^{21-23)}$ や Moli$\operatorname{mard} ら^{24)}$ は, RGB の各強度と膜厚の関係をチャートに しておくことで, SLIM よりも厚い次数の膜厚域まで計 測可能であることを示した。

比色分析法の分解能は高々 $3 \mathrm{~nm}$ 程度, 計測レンジは 最大 $150 \mathrm{~nm}$ と限られているが, 潤滑膜の 3D プロファ イルを容易に得られるという利便性がある。この特徵を 活かして, 表面テクスチャ ${ }^{25)}$, スタベーション ${ }^{26)}$, 境界 潤滑 ${ }^{27,28)}$ ，ナノ粒子潤滑 ${ }^{29)}$ など，現在も幅広い研究対象
で活用されている。

\section{4 白色分光法}

白色分光法は, 白色光源による干涉光を分光器により スペクトル分解して, 強度と波長の関係から膜厚を求め る方法である。Cameronを継いだ Spikes のグループに より，スペーサ層と白色分光法を組合せた手法（超薄膜 光干涉法）が提案されて以来, 最も高精度な潤滑膜厚計 測手法として現在に至っている。まず，Johnston ら ${ }^{30)}$ は, 光強度スペクトルから強度が最大となる波長を求め ることにより, 最小 $1 \mathrm{~nm}$, 最大 $500 \mathrm{~nm}$ の潤滑膜を分解 能 $0.5 \mathrm{~nm}$ で計測できることを示した。同手法により, 脂肪酸が形成する境界潤滑膜の膜厚がはじめて in-situ 計測された。その後, Glovnea ら ${ }^{31)}$ は, 多光束干渉モデ ルに基づき, 最小膜厚 $0.3 \mathrm{~nm}$, 誤差 $0.15 \mathrm{~nm}$ の高精度な 計測手法を確立した。

白色分光法では，比色分析法のように潤滑膜の 3D プ ロファイルを手軽に得ることはできないが, 分光器より も上流にスリットを設けた Fig. 3 のような構成により， 潤滑膜の 2D プロファイルを得ることができる。定常な 潤滑面の計測であれば，計測ユニット全体をスリットの 向きと垂直にスキャンすることにより，潤滑膜の 3D プ ロファイルを得ることも可能である。

\section{4. 白色分光法に関するテクニカルノート}

\section{1 反射率スペクトル}

白色分光法は, サブナノメートルの分解能で潤滑膜を in-situ 計測できる有用な計測手法である。本節では，多 光束干渉理論 ${ }^{32,33)}$ に基づく反射率の計算結果を例示しな がら，本手法のポイントを紹介する。
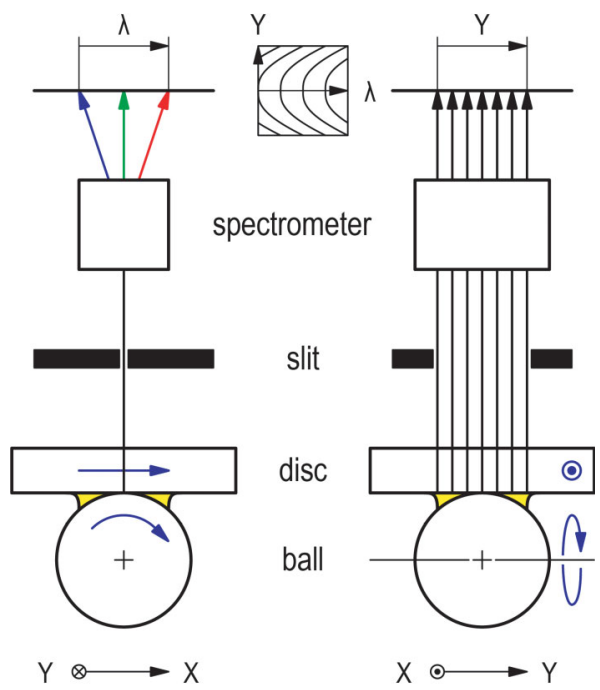

Fig. 3. (color online). Principle of measuring 2D profile of lubricant film by white-light spectroscopy. 
改めて, 反射率 $R=R(\lambda)$ とは, 入射光強度 $I_{\mathrm{in}}=I_{\mathrm{in}}(\lambda)$ と反射光強度 $I_{\text {out }}=I_{\text {out }}(\lambda)$ を用いて,

$$
R=I_{\text {out }} / I_{\text {in }}
$$

で定義される無次元量である。実際の計測では， $I_{\mathrm{in}}$ を 計測するかわりに, 反射率 $R_{\mathrm{R}}=R_{\mathrm{R}}(\lambda)$ が既知のリファレ ンスで反射光強度 $I_{\text {out-R }}=I_{\text {out-R }}(\lambda)$ を計測し, $I_{\text {in }}=I_{\text {out-R }} / R_{\mathrm{R}}$ の関係を用いて，式( 5 )の $R$ を計算することが多い。

以後，本節の計算における光学モデルは, Fig. 2 に準 じて, ガラス板 (BK7), 反射層 $(\mathrm{Cr})$, スペーサ層 $\left(\mathrm{SiO}_{2}\right)$, 潤滑膜 (ヘキサデカン), 金属板 (鋼) の積層 構造とする。各物質の光学定数は, 文献 ${ }^{34)}$ に準じた。

\section{2 反射層の重要性}

Fig. 4 は, スペーサ層厚 $h_{\mathrm{SL}}=500 \mathrm{~nm}$ のとき, 反射率 $R(\lambda)$ にぼす反射層の有無の影響を示したものである。 反射層厚 $h_{\mathrm{RL}}=5 \mathrm{~nm}$ のとき，コントラストの高いスペク トルが得られ, 潤滑膜厚 $h$ の増加に応じてスペクトル全 体が右にシフトする。一方, 反射層がない場合 $\left(h_{\mathrm{RL}}=0\right.$ $\mathrm{nm})$, コントラストの低いスペクトルとなり, 潤滑膜厚 に応じた変化も小さい。これは, Fig. 2 の反射光 1 の強 度が低いからである。逆に, 反射層が厚すぎると, Fig. 2 の反射光 2 の強度が低下し, スペクトルのコントラス トが低下することは自明なので, 反射層厚には最適值が 存在する。一般には， $h_{\mathrm{RL}}=5 \sim 10 \mathrm{~nm}$ に最適值があると されている ${ }^{35)}$ 。

\section{3 スペーサ層の重要性}

Fig. 5 は, 反射層厚 $h_{\mathrm{RL}}=5 \mathrm{~nm}$ のとき，反射率 $R(\lambda)$ に 及ぼすスペーサ層の有無の影響を示したものである。ス

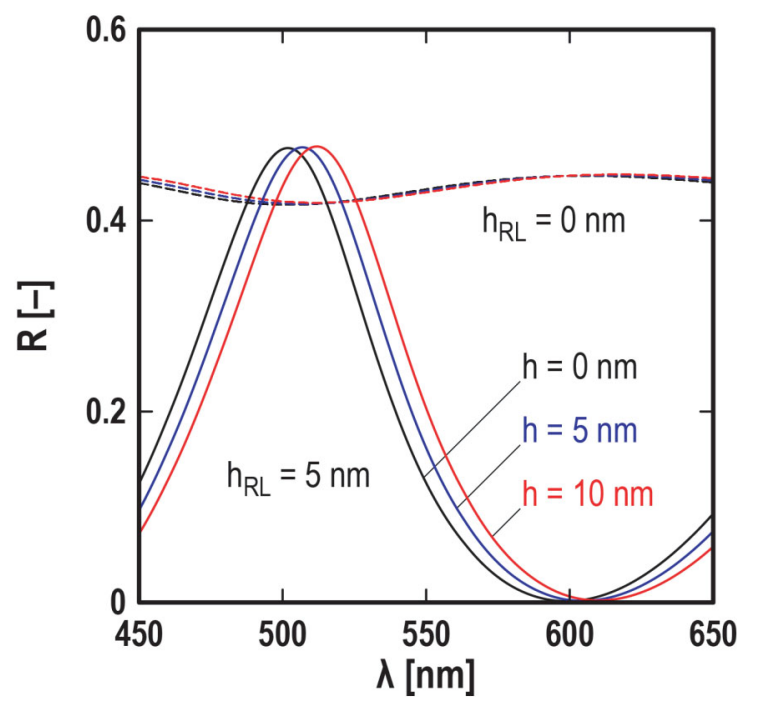

Fig. 4. (color online). Effect of reflective layer (thickness : $h_{\mathrm{RL}}=0,5 \mathrm{~nm}$ ) on reflectance $R(\lambda)$; spacer layer thickness : $h_{\mathrm{SL}}=500 \mathrm{~nm}$; lubricant film thickness : $h=0,5,10 \mathrm{~nm}$.
ペーサ層厚 $h_{\mathrm{SL}}=500 \mathrm{~nm}$ の場合のスペクトルは Fig. 4 と 同じであり，コントラストの高い良好なスペクトルが得 られる。一方，スペーサ層がない場合 $\left(h_{\mathrm{SL}}=0 \mathrm{~nm}\right)$, 潤 滑膜厚の変化に対して強度は変化するものの, スペクト ルのコントラストが低いので，ナノスケールの潤滑膜厚 の計測は一般に容易ではない。スペーサ層がないと， 1 次の干渉（式（1）の $N=1$ と式（2）の $N=1$ ）が現れる 前の反射光に頼ることになるので, 自ずとスペクトルの コントラストは低くなる。本例のように, $500 \mathrm{~nm}$ のス ペーサ層を用いると, 波長の違いにより位相のずれた高 次の干渉（Fig. 5 の $\lambda=500 \mathrm{~nm}$ 付近（式（3）の $N=3$ に 相当）と $\lambda=600 \mathrm{~nm}$ 付近（式（4）の $N=3$ に相当）を利 用することにより, 十分な精度でナノスケールの潤滑膜 厚を計測することができる。

あわせて，単色光の干涉に及ぼす波長の影響を示した Fig. 6 を参照されたい。膜厚 $h=500 \mathrm{~nm}$ 近辺に認められ る波長 $\lambda=500 \mathrm{~nm}$ の極大值と, $h=500 \mathrm{~nm}$ 近辺に認めら れる波長 $\lambda=600 \mathrm{~nm}$ の極小值が, Fig. 4 と Fig. 5 のコン トラストを生み出している。

\section{4 注意点}

本手法を実際に利用するにあたっては，潤滑膜厚の原 点 $(h=0)$ に注意する必要がある。Fig. 1 のような大面 積（たとえば直径 $100 \mathrm{~mm}$ ）のガラス板上にスペーサ層 を作成する以上, スペーサ層厚 $h_{\mathrm{SL}}$ が不均一になること は避けられないからである。したがって, 潤滑膜厚計測 は，トリガを利用するなどして，スペーサ層厚が既知の 特定の位置で実行する必要がある。また，そのスペーサ

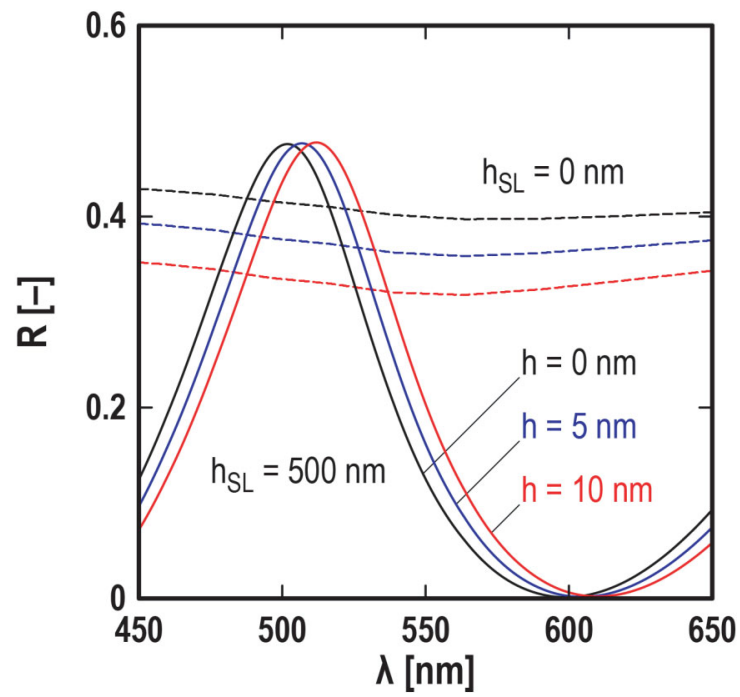

Fig. 5. (color online). Effect of spacer layer (thickness : $h_{\mathrm{SL}}=0,500 \mathrm{~nm}$ ) on reflectance $R(\lambda)$; reflective layer thickness : $h_{\mathrm{RL}}=5 \mathrm{~nm}$; lubricant film thickness $: h=0,5,10 \mathrm{~nm}$. 


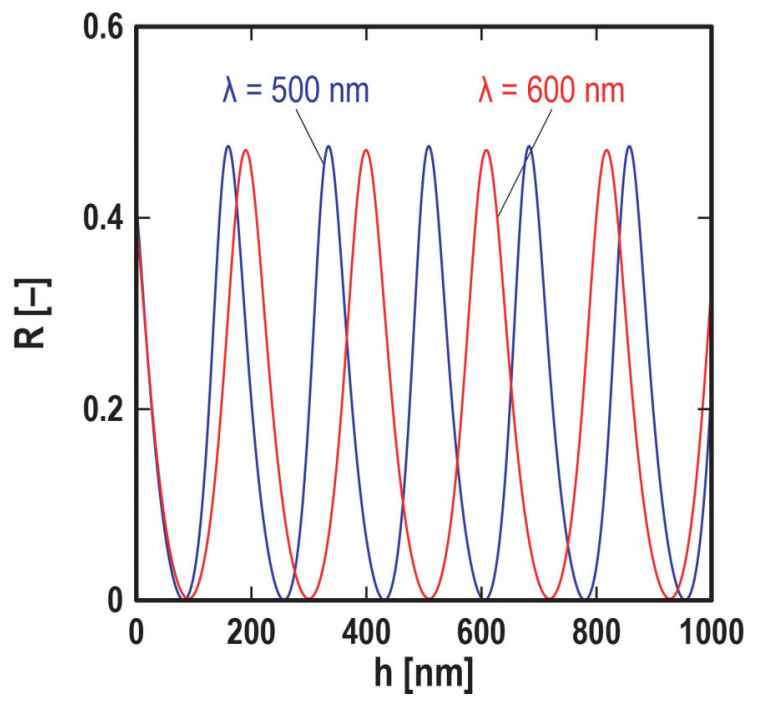

Fig. 6. (color online). Interference of monochromatic light (wavelength : $\lambda=500,600 \mathrm{~nm}$ ); reflective layer thickness : $h_{\mathrm{RL}}=5 \mathrm{~nm}$; spacer layer thickness : $h_{\mathrm{SL}}=0 \mathrm{~nm}$.

層厚は, 対象とする対抗面 (Fig. 1 では金属球) で所望 の負荷をかけた状態で測定する必要がある。負荷により スペーサ層厚がわずかに減少するので，それが潤滑膜厚 の計測誤差として現れるからである。したがって，この 原点出しの作業は, 潤滑油を注入する直前の乾燥状態で なされることが多い。

反射率スペクトルを得た後, 多光束干涉モデルに基づ くフィッティングにより潤滑膜厚を求める場合には, 反 射層厚 $h_{\mathrm{RL}}$ にも注意する必要がある。Fig. 4 で示したよ うに，わずか $5 \mathrm{~nm}$ の層厚で反射率スペクトルに強いコ ントラストが現れることは, 層厚 $0.1 \mathrm{~nm}$ の桁の違いで も, 反射率スペクトルが大きく変化し得ることを意味し ているからである。公表されている論文にスペクトルが 掲載されていることは稀だが，スペクトルのフィッティ ングの良し悪しが本手法の計測精度を左右することはい うまでもない。

\section{5. 流体潤滑から境界潤滑へ}

Fig. 1 のような点接触潤滑面の挙動は, 転がり軸受な どの機械要素技術を念頭に置いて, 弾性流体潤滑 (EHL : elasto-hydrodynamic lubrication) 理論の枠組みで 詳しく調べられてきた。このとき, 潤滑膜厚 $h$ が潤滑油 の粘度 $\eta$ と 2 面の平均速度 $U$ を用いて

$$
h=a(\eta U)^{0.67}
$$

で与えられるという理論的な予測は, 潤滑膜厚計測の結 果を吟味する際の拠り所である。Spikes らにより確立さ れた超薄膜光干渉法（反射層とスペーサ層と白色分光を 組み合わせた手法）のインパクトは, 当初の対象であっ

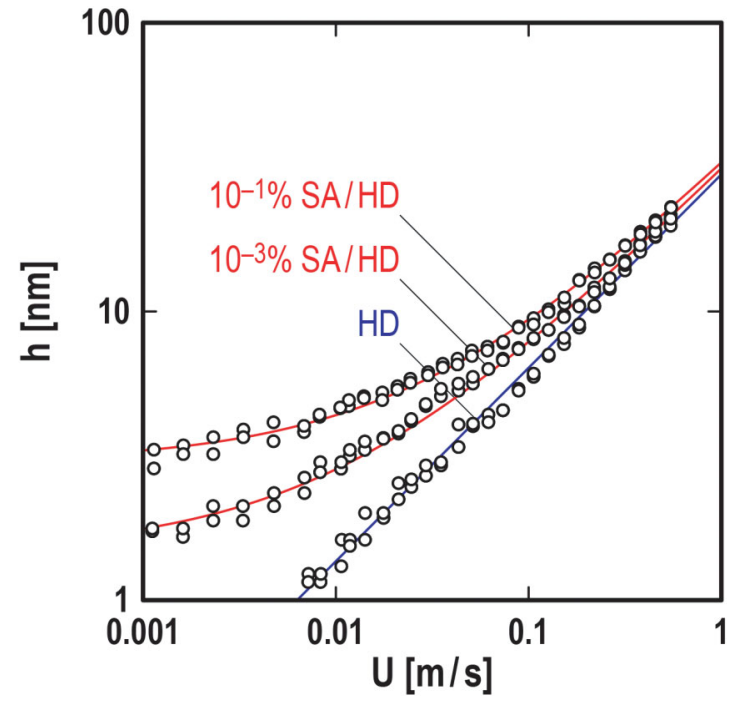

Fig. 7. (color online). Lubricant film thickness $h$ as function of entrainment speed $U$; HD : $n$-hexadecane ; SA/HD : stearic acid solution dissolved in HD.

た流体潤滑の枠組みを超え, EHL 理論からのずれとし て境界潤滑を捉えるアプローチを生んだことにある ${ }^{36) 。 ~}$

たとえば，Fig.7のように，無極性のへキサデカン （HD）の潤滑膜は, 両対数グラフの傾き 0.67 の直線に 沿って $1 \mathrm{~nm}$ まで膜厚が減少するが，極性基を持つステ アリン酸を微量添加した潤滑膜（SA/HD）では，低速 域で上方への明確なずれが生じる。ここで，HDの実験 結果で定まる式 $(6)$ の係数 $a$ はそのままに, 定数 $b$ を加 えた

$$
h=a(\eta U)^{0.67}+b
$$

によって SA/HD の実験結果を良好にフィットできるこ とから，ステアリン酸に由来するナノスケールの境界潤

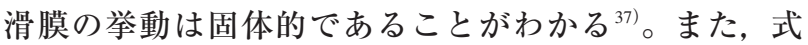
（７）でも実験結果をフィットできないとき，粘度 $\eta を$ 変数と見なして等粘度曲線群を描くことにより，境界潤 滑膜に由来する潤滑油の実効粘度の変化を見積もること ができる ${ }^{38)}$

\section{6. おわりに}

光干渉は光学距離の差により生じる物理現象であり, 光学距離は距離と屈折率の積で与えられる。したがっ て, 本稿で述べた光干渉の理屈は, 距離の変化だけでは なく, 厳密には屈折率の変化にも当てはまる。しかし, 一般的な潤滑油の屈折率の違いは有効数字 2 桁目以下に 現れるので，吸着や化学反応により潤滑膜の一部の物質 が入れ替わったとしても，距離の大きな変化に吸収され てしまうことが多い。すなわち，光干渉による潤滑膜厚 計測は，良くも悪くもロバストな手法であるといえる。 
また，超薄膜光干渉法では，4.4 節で述べたように， 潤滑膜厚の原点 $(h=0)$ を乾燥状態で決める以上, 計測 される膜厚 $h$ は乾燥状態からの変化量であり, 実用上は 不可避な表面粗さの影響を含む量になる。見掛けの接触 面積に支配される流体潤滑とは異なり, 境界潤滑ではむ しろ真実接触面積の概念が重要であり, 負荷を分担する 多数の真実接触点において, どれだけの割合の面積を吸 着膜で被覆できるかが潤滑効果を決める。これらのこと を考えると，（基礎理論が整備されている）流体潤滑の 延長として（基礎理論が未整備な）境界潤滑を眺めるこ とのできるロバストな光干渉の長所を活かしながらも， 摩擦界面での物質の変化に敏感な手法や真実接触の有無 に敏感な手法との併用や融合が，これからの境界潤滑の 進展を加速することは間違いないだろう。

\section{文献}

1) I. Newton: "Opticks” (Dover, New York, 1952).

2) W.B. Hardy and J.K. Hardy: The London, Edinburgh, and Dublin Philosophical Magazine and Journal of Science 38, 32 (1919).

3) M.T. Kirk : Nature 194, 965 (1962).

4) R. Gohar and A. Cameron : Nature 200, 458 (1963).

5) A. Cameron and R. Gohar: Proceedings of the Royal Society of London A : Mathematical, Physical and Engineering Sciences 291, 520 (1966).

6) R. Gohar and A. Cameron : ASLE Transactions 10, 215 (1967).

7) F.J. Westlake and A. Cameron : Nature 214, 633 (1967).

8) C.A. Foord, W. Hammann and A. Cameron : ASLE Transactions 11, 31 (1968).

9) C.A. Foord, L.D. Wedeven, F.J. Westlake and A. Cameron : Proceedings of the Institution of Mechanical Engineers 184, 487 (1969).

10) J. Luo, W. Shizhu and P. Huang: Wear 194, 107 (1996).

11) F. Guo and P.L. Wong: Proceedings of the Institution of Mechanical Engineers, Part J : Journal of Engineering Tribology 216, 281 (2002).

12) R. Bassani and E. Ciulli : Tribology Series 32, 81 (1997).

13) L. Guo, P.L. Wong, F. Guo and H.C. Liu : Applied Optics 53, 6066 (2014).

14) H.C. Liu, F. Guo, L. Guo and P.L. Wong : Tribology Letters 58, 1 (2015).

15) K. Kitagawa and M. Otsuki : Journal of the Japan Society for Precision Engineering 79,1078 (2013).

16) L. Gustafsson, E. Höglund and O. Marklund : Proceedings of the Institution of Mechanical Engineers, Part J :
Journal of Engineering Tribology 208, 199 (1994).

17) P.M. Cann, H.A. Spikes and J. Hutchinson : Tribology Transactions 39, 915 (1996).

18) H.A. Spikes and P.M. Cann: Proceedings of the Institution of Mechanical Engineers, Part J : Journal of Engineering Tribology 215, 261 (2001).

19) J. Lord, A. Jolkin, R. Larsson and O. Marklund : Journal of Tribology 122, 16 (2000).

20) O. Marklund and L. Gustafsson : Proceedings of the Institution of Mechanical Engineers, Part J : Journal of Engineering Tribology 216, 243 (2001).

21) M. Hartl, I. Křupka and M. Liška : Optical Engineering 36, 2384 (1997).

22) M. Hartl, I. Křupka, R. Poliščuk and M. Liška : Tribology Transactions 42, 303 (1999).

23) M. Hartl, I. Krupka, R. Poliscuk, M. Liska, J. Molimard, M. Querry and P. Vergne: Tribology Transactions 44, 270 (2001).

24) J. Molimard, M. Querry and P. Vergne : Tribology Series 36, 717 (1999).

25) G. Guangteng, P.M. Cann, A.V. Olver and H.A. Spikes : Journal of Tribology 122, 65 (1999).

26) F. Chevalier, A.A. Lubrecht, P.M. Cann, F. Colin and G. Dalmaz : Journal of Tribology 120, 126 (1998).

27) L. Taylor, A. Dratva and H.A. Spikes: Tribology Transactions 43, 469 (2000).

28) M. Ratoi, V. Anghel, C. Bovington and H.A. Spikes : Tribology International 33, 241 (2000).

29) F. Chinas-Castillo and H.A. Spikes : Tribology Transactions 43, 387 (2000).

30) G.J. Johnston, R. Wayte and H.A. Spikes : Tribology Transactions 34, 187 (1991).

31) R.P. Glovnea, A.K. Forrest, A.V. Olver and H.A. Spikes : Tribology Letters 15, 217 (2003).

32) O.S. Heavens : "Optical Properties of Thin Solid Films" (Dover, New York, 1991).

33) M. Born and E. Wolf : "Principles of Optics : Electromagnetic Theory of Propagation, Interference and Diffraction of Light (7th Edition)" (Cambridge University Press, Cambridge, 1999).

34) S. Maegawa, J. Yamaguchi, F. Itoigawa and T. Nakamura : Tribology Letters 62, 14 (2016).

35) Z. Fu, F. Guo and P.L. Wong: Tribology Letters 31, 57 (2008).

36) H.A. Spikes : Lubrication Science 14, 147 (2002).

37) K. Nakano and H.A. Spikes: Tribology Online 7, 1 (2012)

38) C. Tadokoro, T. Nihira and K. Nakano : Tribology Letters 56, 239 (2014). 